\title{
Model pembelajaran proyek bermuatan budaya lokal dalam meningkatkan kecerdasan interpersonal dan visual-spasial
}

\author{
Rabihatun Adawiyah \\ Universitas Hamzanwadi Selong. Jalan TGKH Zainuddin Abdul Madjid, No. 132, Lombok \\ Timur, Nusa Tenggara Barat, Indonesia \\ Corresponding Author. Email: rabihatun.el.ishaq45@gmail.com \\ Received: 23 August 2017; Revised: 7 March 2018; Accepted: 28 May 2018
}

\begin{abstract}
Abstrak
Penetian ini bertujuan untuk mengetahui: struktur, kelayakan, dan efektiftas model pembelajaran proyek dengan muatan budaya lokal dalam meningkatkan kecerdasan interpersonal dan visual-spasial anak. Model pengembangan yang digunakan dalam penelitian ini adalah model ADDIE. Model pengembangan ADDIE terdiri dari lima tahap yaitu: Analyze (analisis), design (perancangan), develop (pengembangan), implement (implementasi), dan evaluate (evaluasi). Teknik analisis data menggunakan independent $\mathrm{t}$-test. Hasil dari penelitian ini adalah: (1) struktur pengembangan berupa langkah-langkah model pembelajaran, silabus, RPPM, RPPH, buku panduan guru, (2) produk hasil pengembangan ditinjau dari konsep teori dan media dinyatakan layak digunakan dengan memberikan skor rata-rata "Baik", (3) terdapat perbedaan yang signifikan antara hasil pre perlakuan dan post perlakuan pada kecerdasan interpersonal dan visual-spasial anak kelompok B TK Aisyiah Bustanul Athfal.
\end{abstract}

Kata Kunci: model pembelajaran proyek, budaya lokal, kecerdasan interpersonal, kecerdasan visual-spasial

\section{Developing project study model local culture content in increasing interpersonal and visual-spatial intelligence}

\begin{abstract}
This research aimed to identify: (1) the structure, the feasibility and the effectiveness of the project learning model with the content of local culture in improving the interpersonal and visual-spatial intelligence of the child. The development model which was used in this research was ADDIE model. The development model consisted of five steps, that was: analyze, design, develop, implement, and evaluate. Data analysis technique using independent t-test. The conclusion of the development of project learning model with the content of local culture obtained in this research was: (1) development structure was in the form of learning model steps, syllabus, RPPM, RPPH, teacher manual, (2) development result product from the concept of theory and Media is considered feasible to be used by getting the average score of "Good", (3) there is a significant difference between pre treatment and post treatment result on interpersonal and visual-spatial intelligence of children of group B TK Aisyiah Bustanul Athfal, so that the use of project learning model with local culture content is said to be effective in improving the interpersonal and visual-spatial intelligence of the child.

Keywords: project study model, local culture, interpersonal intelligence, visual-spatial intelligence

How to Cite: Adawiyah, R. (2018). Model pembelajaran proyek bermuatan budaya lokal dalam meningkatkan kecerdasan interpersonal dan visual-spasial. JPPM (Jurnal Pendidikan dan Pemberdayaan Masyarakat), 5(1), 32-40. doi:http://dx.doi.org/10.21831/jppm.v5i1.15436

do) http://dx.doi.org/10.21831/jppm.v5i1.15436
\end{abstract}




\section{JPPM (Jurnal Pendidikan dan Pemberdayaan Masyarakat), 5 (1), 2018 - 33}

Rabihatun Adawiyah

\section{PENDAHULUAN}

Pendidikan Anak Usia Dini ditujukan kepada anak sejak lahir hingga berusia enam tahun untuk menstimulasi setiap perkembangan dan pertumbuhan anak dalam persiapannya memasuki pendidikan lebih lanjut sebagaimana yang dijelaskan dalam Undang-Undang RI Nomor 20 tahun 2003 tentang Pendidikan Anak Usia Dini pasal 1 ayat 14 , dinyatakan bahwa:

"Pendidikan anak usia dini adalah suatu upaya pembinaan yang ditujukan kepada anak sejak lahir sampai berusia enam tahun yang dilakukan melalui pemberian rangsangan pendidikan untuk membantu pertumbuhan dan perkembangan jasmani dan rohani agar anak memiliki kesiapan dalam memasuki pendidikan lebih lanjut".

Pendidikan anak usia dini sangat penting dilaksanakan sebagai dasar bagi pembentukan karakter, budi pekerti luhur, cerdas, dan bertakwa kepada Tuhan yang Maha Esa. Pendidikan anak pada usia awal ini merupakan faktor yang sangat penting dan berpengaruh terhadap masa depan anak itu sendiri, bahkan bagi kemajuan suatu bangsa. Masa ini merupakan masa yang tepat untuk mengoptimalkan pertumbuhan dan perkembangan anak dan meletakkan dasar-dasar pengembangan kemampuan dan kecerdasan.

Kecerdasan bagi anak usia dini sangat penting untuk kehidupannya, baik bagi dirinya sendiri dan kehidupan sosial atau bermasyarakat. Perkembangan kecerdasan anak yang baik akan berpengaruh terhadap bagaimana anak dapat memecahkan masalah atau menemukan solusi terhadap permasalahan-permasalahan yang ditemukan dalam kehidupan sehari-hari. Menurut Gardner (Noorlaila, 2010, p.95) tentang teori kecerdasan jamak (multiple intelligence) terdapat 9 kecerdasan ganda diantaranya verbal-linguistik, logis-matematis, visualspatial, jasmaniah-kinestetik, irama-musikal, intrapersonal, interpersonal, eksistensial.

Dua dari kecerdasan jamak yang disebutkan adalah kecerdasan interpersonal dan visual-spatial. Kecerdasan interpersonal menurut (Gardner, 2013, p.27) adalah "kemampuan untuk memahami orang lain". Kecerdasan interpersonal adalah kemampuan untuk berhubungan dengan orangorang di sekitar, kemampuan untuk memahami dan memperkirakan perasaan, temperamen, suasana, hati, maksud dan keinginanan orang lain dan menanggapinya secara layak. Kecerdasan inilah yang memungkinkan seseorang untuk membangun kedekatan, pengaruh, pimpinan dan membangun hubungan dengan masyarakat.

Melalui pengembangan, kecerdasan akan membantu seseorang untuk menemukan jalan keluar atau solusi permasalahan yang dihadapi dalam kehidupan sehari-hari. Kecerdasan dapat pula membantu seseorang untuk dapat menciptakan sesuatu baik berupa jasa maupun benda dan dapat membantu memudahkan seseorang untuk menyelesaikan persoalan dalam kehidupan sehari-hari (Saleh \& Sugito, 2015, p.86).

Kecerdasan interpersonal ini perlu dibangun sejak usia dini karena sangat penting dalam kehidupan bersama kelompoknya baik teman-teman di sekolah, orang tua, guru, dan masyarakat secara umum. Pada dasarnya manusia tidak bisa menyendiri, banyak kegiatan dalam kehidupan anak yang berkaitan dengan orang lain, sehingga dengan memiliki kecerdasan interpersonal yang tinggi anak tidak mudah tersisihkan secara sosial. Kecerdasan visual-spasial juga penting dalam kehidupan anak, kecerdasan visual-spasial yaitu kemampuan melihat suatu objek dengan sangat detail. Kemampuan ini dapat merekam objek yang dilihat dan didengar serta pengalaman-pengalaman lain dalam memori otaknya dalam jangka waktu yang sangat lama (Suyadi, 2010, p.158). Anak yang memiliki kecerdasan visual yang tinggi biasanya terlihat kontras atau berlainan dengan yang lain. Anak melihat dengan tepat gambaran visual benda-benda yang ada di sekitarnya dengan tingkat kedetailan yang tinggi inilah yang tidak dimiliki oleh kebanyakan anak yang lain. Seseorang banyak tidak menyadari bahwa bekerja hanya mengandalkan satu indra saja, yaitu mata dan mampu menciptakan kembali semua aspek dari objek yang pernah dilihat dengan sangat detail, meskipun objek tersebut telah hilang dari pandangan mata telanjang. 


\section{JPPM (Jurnal Pendidikan dan Pemberdayaan Masyarakat), 5 (1), 2018 - 34 \\ Rabihatun Adawiyah}

Untuk menunjang kecerdasan tersebut perlu lingkungan yang mendukung dalam menstimulasinya. Anak harus dibiasakan berada dalam lingkungan yang positif untuk menghasilkan perilaku yang positif, baik perilaku sosialnya yang berhubungan dengan teman, guru, keluarga dan masyarakat. Lingkungan yang di sekitar anak mencakup keluarga, sekolah dan masyarakat. Budaya menjadi bagian dalam lingkungan tersebut. Lingkungan keluarga, sekolah dan masyarakat yang berbudaya memberi peluang dalam meningkatkan kecerdasan interpersonal dan visual-spatial anak.

Pembelajaran di PAUD menggunakan Kurikulum 2013 dengan menerapkan pembelajaran scientific dalam pembelajaran. Pembelajaran scientific merupakan pembelajaran yang menggunakan tahapan mengamati, mengumpulkan informasi, menganalisis dan menyimpulkan hal ini sesuai dengan model pembelajaran proyek. Pembelajaran proyek adalah model pembelajaran dengan pendekatan konstruktivis dalam belajar. Duffy \& Cunningham (Tamim, \& Grant, 2013, p. 73) model pembelajaran proyek menggunakan pendekatan konstruktivis untuk belajar yang memerlukan konstruksi pengetahuan dengan berbagai perpekstif, baik dalam kegiatan sosial, dan memungkinkan kesadaran diri sendiri dalam belajar. Pembelajaran proyek merupakan tugas yang kompleks, berdasarkan pertanyaan/masalah yang menantang, yang melibatkan peserta didik dalam mendesain, memecahkan masalah, pengambilan keputusan atau kegiatan investigasi, memberikan siswa kesempatan untuk bekerja mandiri dalam waktu yang lama, dan mempresentasikan produk yang dihasilkan.

Menerapkan pembelajaran proyek dalam kurikulum, membantu perkembangan intelektual anak dengan meningkatkan pemikiran mereka melalui observasi dan investigasi terhadap aspek-aspek yang terpilih dari pengalaman dan lingkungan. Pembelajaran pendekatan proyek tidak memiliki struktur dan sangatlah kompleks, tetapi memiliki bingkai kerja yang fleksibel atau tidak kaku dalam proses belajar mengajar. Ketika guru dapat mengimplikasikan pembelajaran pendekatan proyek de- ngan baik, maka pembelajaran pendekatan proyek akan dapat meningkatkan kemampuan anak dan menghasilkan pekerjaan yang berkualitas tinggi Sari, Nuryadin, \& Sujiono, 2014, 59). Menurut Widiastuti (2015, p.71) pembelajaran proyek sebagai sarana untuk menstimulasi kecerdasan majemuk yang dimiliki anak dengan menanamkan nilainilai budaya lokal melalui tema, subtema, alat permainan edukatif, peralatan, dan media sehingga perkembangan anak dapat optimal.

Pengertian kebudayaan dalam antropologi tidak terbatas hanya pada bidangbidang pengetahuan tertentu saja, tetapi mencakup cara bertingkah laku yang dijabarkan atau berasal dari seluruh kegiatan manusia. Kebudayaan tidak hanya mencakup tehnik-tehnik dan metode-metode kesenian dan kesusasteraan, tetapi juga mencakup metode-metode misalnya mendirikan rumah dan sebagainya (Soekamto, 1980, p.81). Hal ini sejalan dengan (Dewantara, 1977, p.274) mengatakan "memasukkan unsur-unsur kebudayaan dalam pembelajaran sangat penting diterapkan di setiap daerah masing-masing hal ini dapat mengembangkan budi pekerti anak".

Kebudayaan sangat berpengaruh terhadap kepribadian seseorang. Dalam pengembangan kepribadian dibutuhkan kebudayaan, dan kebudayaan akan terus berkembang dengan kepribadian tersebut. Sebuah masyarakat yang maju kekuatan penggeraknya adalah orang-orang yang ada di dalamnya. Manusia dan kebudayaan adalah dua hal yang saling berkaitan, manusia dengan akalnya membentuk budaya dan budaya dengan nilai-nilainya menjadi landasan dalam kehidupan bermasyarakat. Pengetahuan budaya lokal sangat peting dimasukkan pada kurikulum sekolah sehingga generasi muda memahami pentingnya pengetahuan budaya lokal. Dalam perkembangan budaya jika tidak mendapat perhatian serius dari seluruh elemen masyarakat maupun pemerintah, maka eksistensi budaya akan mengalami ketertinggalan bahkan mengarah pada hilangnya budaya tersebut.

Penerapan model pembelajaran proyek dengan muatan budaya lokal untuk menstimulasi kecerdasan interpersonal dan visual- 


\section{JPPM (Jurnal Pendidikan dan Pemberdayaan Masyarakat), 5 (1), 2018 - 35}

Rabihatun Adawiyah

spasial anak sehingga sejak dini anak sudah memiliki perkembangan sosial maupun intelektual. Sehubungan dengan hal tersebut, tujuan penelitian ini adalah untuk mengetahui: struktur, kelayakan, dan efektiftas model pembelajaran proyek dengan muatan budaya lokal dalam meningkatkan kecerdasan interpersonal dan visual-spasial anak

\section{METODE}

Penelitian ini menggunakan desain Reseach \& Development model ADDIE. ADDIE terdiri dari lima tahap yaitu: Analyze (analisis), design (perancangan), develop (pengembangan), implement (implementasi), dan evaluate (evaluasi). Produk yang dikembangkan berupa silabus, Rencana Pelaksanaan Pembelajaran Mingguan (RPPM), Rencana Pelaksanaan Pembelajaran Harian (RPPH), buku panduan guru pembelajaran proyek dengan muatan budaya lokal.

Desain uji coba pengembangan model pembelajaran proyek yang dilakukan dalam penelitian ini diawali dengan melakukan validasi produk oleh ahli materi dan ahli media pembelajaran. Setelah produk yang dikembangkan dinyatakan layak untuk diujicobakan selanjutnya dilakukan uji coba produk pada satu sekolah pada TK Aisyiah Bustanul Athfal Pancor Lombok Timur. Uji produk yang digunakan dalam penelitian ini adalah quasi experimental design (eksprimen semu) dengan design non-equivalent kontrol group design kelompok eksperimen maupun kelompok kontrol tidak dipilih secara random. Populasi subjek penelitian kelompok B TK Aisyiah Bustanul Athfal terdiri dari 101 anak. Penentuan sampel dilakukan menggunakan rumus slovin sehingga jumlah sampel didapatkan sebanyak 8 o anak.

Teknik dan instrumen pengumpulan data yaitu wawancara, unjuk kerja anak, dan observasi aktivitas guru. Wawancara menggunakana pedoman wawancara sebagai bahan untuk menganalisis kebutuhan dari informasi yang didapatkan tentang pertanyaan seputar keterlaksanaan kurikulum 2013 di lingkungan sekolah, baik dalam kegiatan pembelajaran, sarana prasarana, dan kesiapan pihak sekolah dalam menjalankan kuri- kulum 2013 dalam meningkatkan kecerdasan interpersonal dan visual-spasial anak, Model wawancara yang digunakan adalah model wawancara tertutup. Lembar observasi digunakan untuk mencatat pengamatan terhadap kegiatan pembelajaran yang dilakukan oleh guru dengan menggunakan produk yang telah dikembangkan, observasi yang digunakan dalam penelitian ini adalah observasi terstruktur menggunakan skala likert dengan empat pilihan berbentuk check list menggunakan rentang nilai dalam bentuk angka $(1,2,3,4,5)$. Untuk penilaian keterlaksanaan pembelajaran yang berarti angka $\mathbf{5}=$ Sangat Tinggi, 4 = Tinggi, $3=$ Sedang, $2=$ Kurang dan $\mathbf{1}=$ Sangat Kurang .

Tabel 1. Skala likert (Widoyoko, 2009)

\begin{tabular}{cc}
\hline Skor Siswa & Klasifikasi \\
\hline $\mathrm{X} \geq \bar{X} i+1,8 \mathrm{xSbi}$ & Sangat Baik \\
$\bar{X}+0,6 \mathrm{xsbi}<\mathrm{X} \leq \bar{X} \iota+1.8 \mathrm{xsbi}$ & Baik \\
$\bar{X}-\mathrm{o}, 6 \mathrm{xsbi}<\mathrm{X} \leq \bar{X} \iota+0,6 \mathrm{xsbi}$ & Cukup \\
$\bar{X}-\mathrm{o}, 6 \mathrm{xsbi}<\mathrm{X} \leq \bar{X} \iota-0,6 \mathrm{xsbi}$ & Kurang \\
$\mathrm{X} \geq \bar{X} i-1,8 \mathrm{xSbi}$ & Sangat Kurang \\
\hline
\end{tabular}

Tabel 2. Kriteria Penilaian (Widoyoko, 2009)

\begin{tabular}{ccc}
\hline $\begin{array}{c}\text { Persentase } \\
\text { Ketuntasan }\end{array}$ & Klasifikasi & Skor \\
$>80$ & Sangat Baik & 5 \\
$>60-80$ & Baik & 4 \\
$>40-60$ & Cukup & 3 \\
$>20-40$ & Kurang & 2 \\
$\leq 20$ & Sangat Kurang & 1 \\
\hline
\end{tabular}

Lembar unjuk kerja digunakan untuk melihat peningkatan kecerdasan interpersonal dan visual-spasial anak dengan menggunakan model pembelajaran proyek muatan budaya lokal menggunakan check list dengan nilai ya dan tidak dalam bentuk angka $\mathbf{1}=$ Ya dan $\mathbf{o}=$ Tidak. Uji efektifitas produk pengembangan yaitu uji statistika independent $t$-test dengan program SPSS 23,00 for Windows. Ada dua uji prasyarat yang harus dilakukan sebelum uji independent ttest yaitu uji normalitas data dan uji homogenitas data. Kriteria penilaian disusun pada Tabel 2.

\section{HASIL DAN PEMBAHASAN}

Uji coba produk dilakukan di TK Aisyiah Bustanul Athfal (ABA) Pancor Lombok Timur dilaksanakan pada tanggal 20 


\section{JPPM (Jurnal Pendidikan dan Pemberdayaan Masyarakat), 5 (1), 2018 - 36}

Rabihatun Adawiyah

Februari sampai dengan 30 Maret 2017 yaitu sebanyak 16 kali pertemuan 4 kali dalam seminggu. Uji coba dilakukan untuk melihat efektifitas dari produk yang dikembangkan apakah dapat meningkatkan kecerdasan interpersonal dan visual-spasial anak kelas B TK ABA Pancor, subjek uji coba melibatkan 8o anak pada kelas B dari 101 anak, ukuran sampel didapatkan berdasarkan rumus slovin. Sebanyak 40 anak kelompok eksperimen dan 40 anak dalam kelompok kontrol dengan dua orang guru dalam setiap kelompok eksperimen. Hasil dari unjuk kerja anak didapatkan dapat dilihat Tabel 3.

Berdasarkan hasil analisis tersebut, menunjukkan bahwa rata-rata total dan ratarata ketuntasan pre perlakuan pada kelompok eksperimen untuk kecerdasan interpersonal adalah $55,11 \%$ dan $42,5 \%$ dengan kategori ketuntasan "CUKUP”, post perlakuannya yaitu $74,5 \%$ dan $85 \%$ dengan kategori ketuntasan "SANGAT TINGGI". Kemudian untuk kelompok kontrol yaitu pre perlakuan 56,07\% dan 50\% dengan kategori ketuntasan "CUKUP", post perlakuannya menunjukkan $65,23 \%$ dan $60 \%$ dengan kategori ketuntasan "BAIK". Dari hasil tersebut dapat dilihat bahwa untuk kecerdasan interpersonal mengalami peningkatan baik pada kelompok eksperimen maupun kelompok kontrol. Akan tetapi pada kelompok eksperimen peningkatannya jauh lebih tinggi dari pada kelompok kontrol. Kelompok eksperimen sudah memenuhi kriteria minimal "BAIK".

Rata-rata total dan rata-rata ketuntasan kecerdasan visual-spasial pada kelompok eksperimen menunjukkan untuk pre perlakuan sebesar $54,16 \%$ dan $45 \%$ lalu post perlakuan sebesar $71,07 \%$ dan $75 \%$. Sedangkan pada kelompok kontrol menunjukkan untuk pre perlakuan 57,73\% dan ketuntasan 52,2 \%. Pada post perlakuan rata-rata skor $65,59 \%$ dan rata-rata ketuntasan $65 \%$. Baik kelompok eksperimen maupun kelompok kontrol mengalami peningkatan. Pada kelompok eksperimen peningkatannya jauh lebih tinggi dari pada kelompok kontrol. Hal ini menunjukkan bahwa terdapat peningkatan kecerdasan interpersonal dan visual-spasial pada kelompok eksperimen maupun kelompok kontrol.

\section{Uji efektivitas dengan independent T- test}

Berdasarkan deskripstif statistik data kecerdasan interpersonal dan visual-spasial maka didapatkan perbedaan yang menggunakan pembelajaran dengan menerapkan model pembelajaran proyek dengan muatan budaya (kelompok eksperimen) dibandingkan dengan anak yang menggunakan model pembelajaran konvensional (kelompok kontrol). Hasil uji independent t-test dapat dilihat Tabel 4 .

Tabel 3. Deskripsi Data Hasil Pre Perlakuan dan Post Perlakuan dalam Kelompok Kontrol dan Kelompok Eksperimen

\begin{tabular}{ccccc}
\hline \multirow{3}{*}{ Deskripsi } & \multicolumn{5}{c}{ Kecerdasan Interpersonal } \\
\cline { 2 - 5 } & \multicolumn{5}{c}{ Eksperimen } & post & pre & Post \\
\cline { 2 - 5 } & pre & $74,5 \%$ & $56,07 \%$ & $65,23 \%$ \\
Rata total & $55,11 \%$ & $85 \%$ & $50 \%$ & $60 \%$ \\
Rata tuntas & $42,5 \%$ & \multicolumn{5}{c}{ Kecerdasan Visual-Spasial } \\
\hline \multirow{3}{*}{ Deskripsi } & \multicolumn{5}{c}{ Eksperimen } & post & pre & Post \\
\cline { 2 - 5 } & pre & $71,07 \%$ & $57,73 \%$ & $65,59 \%$ \\
\cline { 2 - 5 } & $54,16 \%$ & $75 \%$ & $52,5 \%$ & $65 \%$ \\
Rata total & $45 \%$ & \multicolumn{4}{c}{. }
\end{tabular}

Tabel 4. Hasil Uji Independent T-Test Pre Perlakuan dan Post Perlakuan Kecerdasan Interpersonal pada Kelompok Eksperimen dan Kontrol

Interpersonal kelompok eksperimen

Interpersonal kelompok control
Equal variances assumed Equal variances not assumed Equal variances assumed Equal variances not assumed
Sig. (2-tailed)

.000

.000

0.020

0.020 
JPPM (Jurnal Pendidikan dan Pemberdayaan Masyarakat), 5 (1), 2018 - 37

Rabihatun Adawiyah

Tabel 4. Hasil Uji Independent T-Test Pre Perlakuan dan Post Perlakuan Kecerdasan VisualSpasial pada Kelompok Eksperimen dan Kontrol

\begin{tabular}{ccc}
\hline & & Sig. (2-tailed) \\
Visual-spasial kelompok eksperimen & Equal variances assumed & .ooo \\
& Equal variances not assumed & .ooo \\
Visual-spasial kelompok control & Equal variances assumed & 0.027 \\
& Equal variances not assumed & .027 \\
\hline
\end{tabular}

Tabel 5. Hasil Uji Independent T-Test antara Post Perlakuan Kecerdasan Interpersonal dan Visual-Spatial pada Kelompok Eksperimen dan Kontrol

\begin{tabular}{ccc} 
& & Sig. (2-tailed) \\
Interpersonal & Equal variances assumed & .011 \\
& Equal variances not assumed & .011 \\
Visual-spasial & Equal variances assumed & .027 \\
& Equal variances not assumed & .027 \\
\hline
\end{tabular}

Berdasarkan Tabel 3 dapat dilihat untuk kecerdasan interpersonal dari kelompok eksperimen maupun kontrol menunjukkan nilai signifikansi uji sig. (2-tailed) kurang dari $(<0,05)$, maka dapat disimpulkan terdapat perbedaan peningkatan antara kecerdasan interpersonal pada pre perlakuan dan post perlakuan. Kelompok eskperimen pada pre perlakuan dan post perlakuan yang menggunakan model pembelajaran proyek dengan muatan budaya lokal memiliki perbedaan yang signifikan yaitu o.ooo sedangkan pada kelompok kontrol signifikansi antara pre perlakuan dan post perlakuan yaitu 0.020.

Berdasarkan Tabel 4 dapat dilihat untuk kecerdasan visual-spasial dari kelompok eksperimen maupun kontrol menunjukkan nilai signifikansi uji sig. (2-tailed) kurang dari $(<0,05)$, maka dapat disimpulkan terdapat perbedaan peningkatan antara kecerdasan visual-spasial pada pre perlakuan dan post perlakuan. Kelompok eskperimen pada pre perlakuan dan post perlakuan yang menggunakan model pembelajaran proyek dengan muatan budaya lokal memiliki perbedaan yang signifikan yaitu o.ooo sedangkan pada kelompok kontrol signifikansi antara pre perlakuan dan post perlakuan yaitu 0.027 .

Berdasarkan Tabel 5 dapat dilihat untuk kecerdasan interpersonal dan visualspasial setelah diberikan perlakuan pada kelompok eksperimen (menggunakan model pembelajaran proyek dengan muatan budaya lokal) maupun kontrol (menggunakan mo- del konvensional) bahwa nilai signifikansi uji sig. (2-tailed) kurang dari $(<0,05)$, maka dapat disimpulkan terdapat perbedaan peningkatan antara kecerdasan interpersonal dan visual-spasial pada kelompok eksperimen dan kelompok kontrol.

\section{Pembahasan}

Berdasarkan hasil penelitian dapat disimpulkan bahwa kecerdasan interpersonal dan visual-spasial anak kelompok B TK Aisyiah Bustanul Athfal Pancor Lombok Timur dapat meningkat melalui model pembelajaran proyek dengan muatan budaya lokal. Persentase ketuntasan pada kecerdasan interpersonal dan visual-spasial anak meningkat, hal ini dapat dilihat dari hasil unjuk kerja pre perlakuan dan post perlakuan pada kelas eksperimen.

Model pembelajaran proyek dapat meningkatkan kecerdasan kecerdasan interpersonal anak seperti yang dikatakan (Lin, Moore, \& Jang, 2012, p.5) bahwa dengan memecahkan masalah akan meningkatkan kemampuan berpikir dan komunikasi anakanak. Anak menjadi lebih percaya diri untuk berbicara di depan orang lain begitu juga dengan keterampilan sosial anak lebih meningkat karena kegiatan proyek melalui kelompok hal ini dikuatkan oleh hasil penelitian (Saemah, 2012, p.111) dalam jurnalnya mengatakan bahwa hasil penelitian mendukung proposisi untuk mengadopsi pendekatan berbasis proyek di lingkungan prasekolah, pelaksanaan pembelajaran proyek membantu memberikan lingkungan 


\section{JPPM (Jurnal Pendidikan dan Pemberdayaan Masyarakat), 5 (1), 2018 - 38}

Rabihatun Adawiyah

belajar yang merangsang perkembangan kognitif, sosial dan emosional anak dengan cara yang me-nyenangkan dan bermakna. Metode proyek memiliki beberapa tujuan menurut Katz dan Chard (Kostelnik, Soderman, Whiren \& Rupiper, 2007, p.516) adalah (a) memperoleh pengetahuan dan keterampilan (b) meningkatkan kompetensi sosial, (c) mengembangkan disposisi atau karakter, dan (d) mengembangkan perasaan yang berkaitan dengan pengalaman sekolah.

Mills \& Treagust (2003, p.9) mengatakan bahwa Anak bekerja dalam kelompokkelompok kecil dengan tim proyek dan guru sebagai penasihat atau pembimbing. Kegiatan proyek anak dalam kelompok yang dilakukan bersama-sama sangat berpengaruh terhadap kemampuan interpersonal anak. Hal ini sejalan dengan Gardner (Jackman, 2009, p.12) mengatakan bahwa lingkungan belajar harus memberikan kesempatan bagi anak-anak untuk berhubungan dengan orang lain dengan bersama-sama berpartisipasi, berbagi, bernegosiasi, belajar melalui mendengarkan masyarakat, bekerja sama dalam proyek-proyek bersama, terampil dalam memimpin, melihat sesuatu dari perspektif lain, dan mengorganisir dan negosiasi kegiatan group.

Dari tujuan model pembelajaran tersebut sesuai dengan pengertian dari (Safaria, 2005, p.24) bahwa kecerdasan interpersonal atau disebut juga sebagai kecerdasan sosial, yang diartikan sebagai kemampuan dan keterampilan seseorang dalam menciptakan hubungan, membangun hubungan dan mempertahankan hubungan sosialnya. Namun kedua kata ini yaitu sosial maupun interpersonal menjelaskan hal yang sama yaitu kemampuan untuk meciptakan, membangun dan mempertahankan suatu hubungan antar pribadi (sosial) yang sehat dan saling menguntungkan. Jadi melalui model pembelajaran proyek dengan muatan budaya lokal terlihat dapat meningkatkan kecerdasan interpersonal anak.

Secara sederhana, anak yang mempunyai kecerdasan visual tinggi mempunyai ciri-ciri sebagai berikut (Suyadi, 2010, p.161) mampu menghitung dengan cara mangawang atau mencongak, mampu membuat benda seperti yang tergambar dalam pikirannya, mampu mengarang cerita pendek. Kemampuan tersebut dapat di tingkatkan melalui pembelajaran proyek karena hal ini sejalan dengan tujuan kegiatan proyek menurut Kazt dan Chart yaitu untuk berpikir tentang konten dan belajar pengetahuan tentang konten tertentu. Hal ini menerapkan keterampilan intelektual dan sosial anak, mengembangkan disposisi yang positif terhadap penemuan dan penyelidikan, dan mengembangkan keterampilan dalam menggunakan sumber daya yang ada (Kostelnik, Soderman, Whiren \& Rupiper, 2007, p.516). Sejalan dengan kecerdasan visual-spasial menurut (Mulyasa, 2014, p.113) bahwa model pembelajaran proyek dapat memberikan peluang kepada setiap anak baik individual maupun kelompok untuk mengembangkan kemampuan yang telah dimilikinya, keterampilan yang sudah dikuasainya yang pada akhirnya dapat mewujudkan daya kreativitasnya secara optimal.

Model pembelajaran proyek dengan muatan budaya lokal dapat meningkatkan kecerdasan interpersonal dan visual-spasial anak tidak dapat lepas dari aktivitas guru. Hal ini dapat berjalan dengan baik dikarenakan guru melakukan langkah-langkah yang sesuai dengan ketentuan. Hasil observasi tiga guru pada kelompok eksperimen menunjukkan bahwa aktivitas guru pada ratarata sangat baik. Hal ini sejalan dengan (Sari, Nuryadin, Sujiono, 2014, p.59) bahwa ketika guru dapat mengimplikasikan pembelajaran pendekatan proyek dengan baik, maka pembelajaran pendekatan proyek akan dapat meningkatkan kemampuan anak dan menghasilkan pekerjaan yang berkualitas tinggi.

\section{SIMPULAN}

Berdasarkan hasil penelitian dan pembahasan yang sudah didapatkan dapat disimpulkan yaitu: struktur model pembelajaran proyek dengan muatan budaya lokal dalam meningkatkan kecerdasan interpersonal dan visual-spasial anak yaitu mengembangkan produk berupa perangkat pembelajaran untuk anak usia dini pada kelompok B yaitu berupa langkah-langkah model pembelajaran proyek dengan muatan budaya lokal, silabus, RPPM, RPPH, dan buku panduan untuk guru, Produk hasil pengembang- 
an model pembelajaran proyek dengan muatan budaya lokal dalam meningkatkan kecerdasan interpersonal dan visual-spasial ditinjau dari konsep teori dan media dinyatakan layak digunakan dengan memberikan rata-rata skor "Baik", produk yang dikembangkan berupa perangkat pembelajaran dikatakan layak ditinjau dari konsep teori yaitu dengan kategori untuk langkah-langkah model pembelajaran proyek dengan muatan budaya lokal (Baik), silabus (baik), RPPM (sangat baik), RPPH (sangat baik), buku panduan guru (sangat baik), produk yang dikembangkan berupa perangkat pembelajaran dikatakan layak ditinjau dari konsep media dengan kategori yaitu untuk silabus (baik), RPPM (baik), RPPH (baik), buku panduan guru (baik), produk hasil pengembangan model pembelajaran proyek dengan muatan budaya lokal dalam meningkatkan kecerdasan interpersonal dan visual-spasial ditinjau dari konsep teori dan media dinyatakan layak digunakan dengan memberikan rata-rata skor "baik".

\section{DAFTAR PUSTAKA}

Dewantara, K.H. (1977). Bagian pertama pendidikan. Yogyakarta: Persatuan taman Siswa.

Gardner, H. (2013). Multiple intelligence: Memaksimalkan potensi $\mathcal{E}$ kecerdasan individu dari masa kanak-kanak hingga dewasa (Terjemahan Alexander Sindoro). Tangerang Selatan: interaksara.

Jackman, H. L. (2009). Early education curriculum: A child's connection to the word internasional edition. United States: Wadsworth Cengage Learning.

Kostelnik, M. J., Soderman, A. K., Whiren, A. P., \& Rupiper, M. L. (2007). Developmentally appropriate curriculum: Best practices in early childhood education 4th. New Jersey: Pearson Prentice Hall.

Lin, Y.M, Moore, L \& Jang, L.A. (2012). The power of projects incorporating the project approach in the preschool and primary curriculum in varied ways: Incorporating the Project Approach in Preschool. A journal for education of and advocacy for young children, vol 31, number 1.

Mills, J. E \& Treagust, D.F. (2003). Engineering education is problembased or project-based learning the snswer?. Australasian J. Of Engng. Educ., online publication 200304 http:// www.aaee.com.au/journal $/ 2003 / \mathrm{mills}$ treagusto3.pdf

Mulyasa, H.E. (2014). Manajemen PAUD. Bandung: PT Remaja Rosdakarya

Noorlaila, I. (2010). Panduan lengkap mengajar PAUD: Kreatif mendidik dan bermain bersama anak. Yogyakarta: Pinus Book Publisher.

Saemah. (2012). Project-based approach at preschool setting. Faculty of Education, Universiti Kebangsaan Malaysia, 43600 Bangi, Selangor, Malaysia. World Applied Sciences Journal 16 (1): 106-112, 2012 ISSN 1818-4952, IDOSI Publications, 2012.

Safaria, T. (2005). Interpersonal intelligence: Metode pengembangan kecerdasan interpersonal anak. Yogyakarta: Amara Books

Saleh, S., \& Sugito, S. (2015). Implementasi metode bermain peran untuk meningkatkan kecerdasan interpersonal anak usia 5-6 tahun di TK Barunawati. JPPM (Jurnal Pendidikan dan Pemberdayaan Masyarakat), 2(1), 85-93. doi:http://dx.doi.org/10.21831/jppm.v2i 1.4845

Sari, W.W., Nuryadin, S., \& Sujiono, Y.N. (2014). Peningkatan kemampuan sains melalui pendekatan proyek. Jurnal pendidikan usia dini Volume 8 Edisi I.

Soekamto. (1980). Petunjuk guru antropologi budaya. Jakarta: Departemen Pendidikan dan Kebudayaan.

Suyadi. (2010). Psikologi belajar pendidikan anak usia dini. Yogyakarta: Pedagogia

Tamim, S.R., \& Grant, M.M. (2013). Definitions and uses: Case study of teachers implementing project-based 
JPPM (Jurnal Pendidikan dan Pemberdayaan Masyarakat), 5 (1), 2018 - 40

Rabihatun Adawiyah

learning. Volume 7 Published online: 516-2013.

Widiastuti, S. (2015). Pembelajaran proyek berbasis budaya lokal untuk menstimulasi kecerdasan majemuk anak usia dini. Jurnal pendidikan anak, $1(1)$.
Widoyoko, E.P. (2009). Evaluasi program pembelajaran panduan praktis bagi pendidik dan calon pendidik. Yogyakarta: Pustaka Pelajar.

Sari, W. W., Nuryadin, S., \& Sujiono, Y. N. (2014). Peningkatan kemampuan sains melalui pendekatan proyek. Jurnal Pendidikan Usia Dini, 8(1), 55-64. 